\title{
Seasonal Occurrence of a Predaceous Mite Amblyseius addoensis Van der Merwe \& Ryke (Acari: Phytoseiidae) on Table Grapes
}

\author{
A. Schwartz \\ Viticultural and Oenological Research Institute, Private Bag X5026, 7600 Stellenbosch, Republic of South Africa. \\ Submitted for publication: May 1987 \\ Accepted vor publication: July 1987 \\ Keywords: Predaceous mite, Phytoseiidae, seasonal occurrence, table grapes, Vitis
}

\begin{abstract}
Predaceous mites (Phytoseiidae) and their importance as biological control agents, especially in fruit tree culture, are well documented. These mites are primarily predators of the Tetranychidae.

Amblyseius addoensis Van der Merwe \& Ryke was first identified on vines in 1964 (Van der Merwe \& Ryke, 1964). Dennill (1986) recorded the presence of $A$. addoensis, along with other predators, in growth buds during a study of the vine bud mite, Colomerus vitis (Pagst.). During the course of a recent study on the seasonal occurrence of thrips (Thrips tabaci Lindeman) in vineyards in the Western Cape, A. addoensis was found in leaf samples and this presented an opportunity to investigate the seasonal occurrence of this mite.
\end{abstract}

\section{MATERIALS AND METHODS}

The study was carried out over two seasons $(1984 / 85 \&$ 1985/86) on Waltham Cross and over a single season $(1984 / 85)$ on Queen of the Vineyard in the Paarl area, for the period post blossom to leafdrop. Both vineyards were subjected to a standard spray programme for the control of diseases, with no insecticidal sprays being applied. A shoot was selected as sampling unit, from which the terminal $150 \mathrm{~mm}$ (with attached leaves), one middle position leaf and one basal leaf were sampled. These parts were cut into a jar containing a 70 percent ethyl alcohol solution. Sampling was done bi-weekly on a single plant per plot of five plants, for each of five plots in a row and for 10 rows in the vineyard, i.e. a total of 50 units per vineyard. The jar was shaken to dislodge any organisms from the leaves. Next the leaves were removed with forceps and the jars taken to the laboratory. After standing overnight the excess solution was drawn off and the rest with the precipitant, poured into a petri dish. The bottom of the dish was graded to facilitate counting. All motile stages of $A$. addoensis and T. tabaci were counted

\section{RESULTS AND DISCUSSION}

As indicated in Fig. 1 the population peaks for T. tabaci on Queen of the Vineyard occurred during February. Following the decline in the thrips population, A. addoensis increased dramatically reaching very high numbers just prior to normal leaf drop. It is assumed that the majority of the predaceous mites would perish after leafdrop, but those that had migrated to the buds on canes would overwinter and survive, as established by Dennill (1986).

The results presented in Fig. 2 for Waltham Cross are in agreement with those that were recorded for Queen of the Vineyard, viz. a population peak for $T$. tabaci during February followed by a rapid increase of the predator during the subsequent months until leafdrop.

The only recognisable phytophagous organism in the leaf samples was $T$. tabaci. Although the A. addoensis population lagged behind that of $T$. tabaci and conse- quently was unable to reduce the pest numbers effectively, it nevertheless appears to have utilised the latter to its advantage. This assumption is supported by laboratory observations which indicated that $A$. addoensis feeds on the nymphs of $T$. tabaci.

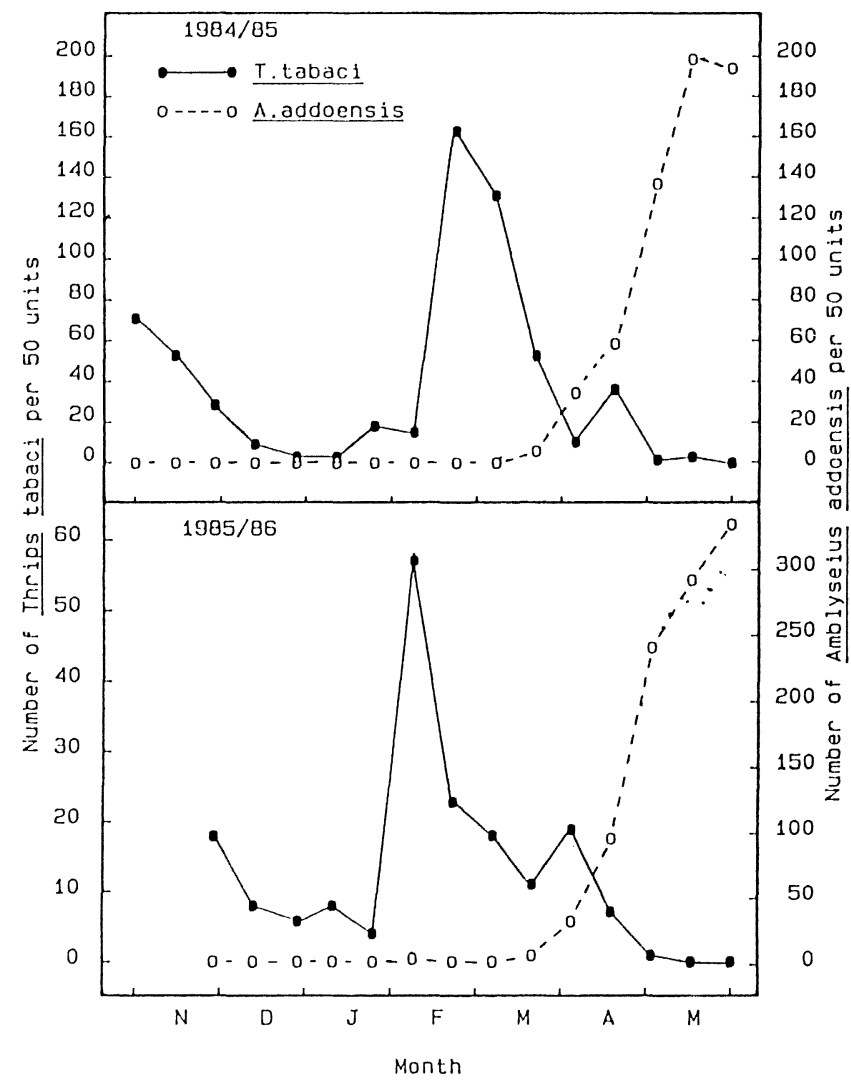

FIG. 1

Seasonal occurrence of Amblyseius addoensis Van der Merwe \& Ryke in relation to Thrips tabaci Lindeman on the leaves of Queen of the Vineyard (post blossom to leaf drop). 


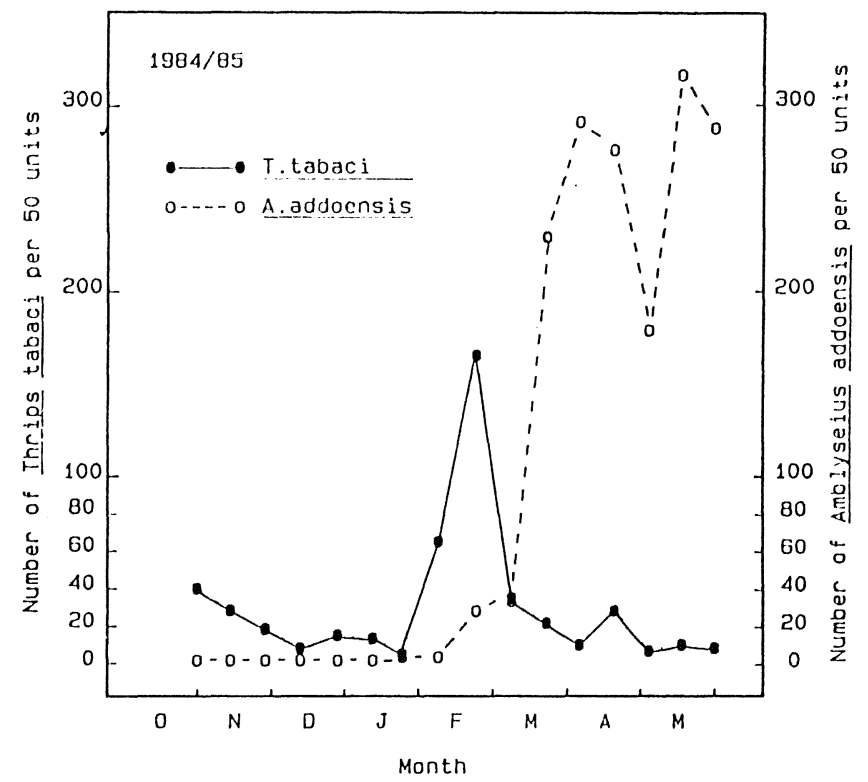

FIG. 2.

Seasonal occurrence of Amblyseius addoensis Van der Merwe \& Ryke in relation to Thrips tabaci Lindeman on the leaves of Waltham Cross (post blossom to leaf drop).

Subsequent to the present study $A$. addoensis was found in association with Oligonychus vitis Zaher \& Shehata (Tetranychidae) at Wolseley in the Western Cape (unpublished data). Moreover, Keetch (1968) demonstrated that $A$. addoensis was a very important natural enemy of the citrus red mite, Panonychus citri (McG.) (Tetranychidae) in the Eastern Cape. A closely related predaceous mite, i.e. Amblyseius citri Van der Merwe \& Ryke, was found to prey upon the citrus thrips, Scirtothrips aurantii Faure, in the Transvaal Lowveld (Schwartz, 1983). Although it is commonly re- cognised that predaceous mites are omnivorous, they prey mainly on members of the Tetranychidae. Alternative food taken by phytoseiids include the immature stages of many insect and mite species such as thrips, scale, eriophyid mites as well as nectar, pollen, fungus spores and even plant juice (McMurtry. Huffaker \& Van de Vrie, 1970). This characteristic enables the predaceous mite to survive on the plant in the absence of its preferred prey.

\section{CONCLUSION}

The study serves to demonstrate the presence and population trends of a beneficial mite, viz. A. addoensis on leaves of two table grape cultivars in the Western Cape. The predaceous mite population followed a definite seasonal pattern with colonisation of the leaves taking place fairly late in the season and maximum numbers being reached during May. It is logical to assume that there should be a reason for this phenomenon, namely that $A$. addoensis preyed upon the only other living species, i.e. T. tabaci which was present on the leaves. Asynchronous population peaks due to inherent requirements of the two species are thought to be the reason for the predator's inability to reduce the mid-summer build-up of $T$. tabaci.

\section{REFERENCES}

DENNILL, G.B., 1986. An ecological basis for timing control measures against the grape vine bud mite Eriophyes vitis Pgst. Crop Protection 5(1), 12-14.

KEETCH, D.P., 1968. Some aspects of the ecology of the citrus red mite, Panonychus citri (McG.) in the Eastern Cape province. M.Sc. Thesis, Rhodes University, Grahamstown, Republic of South Africa

McMURTRY, J.A., HUFFAKER, C.B. \& VAN DE VRIE, M. 1970. Ecology of Tetranychid mites and their natural enemies: A Review. Hilgardia 40, 331-458.

SCHWARTZ, A., 1983. Sitrusblaaspootjie: Wat van biologiese beheer? Subtropica 4(2), 14.

VAN DER MERWE, G.G. \& RYKE, P.A.J., 1964. The subgenus Typhlodromalus Muma of the genus Amblyseius Berlese in South Africa (Acarina: Phytoseiidae). J. Ent. Soc. Sth. Afr. 26, 263-289. 